\title{
Hydroxychloroquine and risk of cardiac decompensation
}

Lindsey Tilling

Royal Berkshire Hospital Reading; Dr Sacha Bull, Royal Berkshire Hospital Reading RG1 5AN UK

Corresponding Author: Lindsey Tilling, Royal Berkshire Hospital, Craven Road, Reading RG1 5AN UK. Telephone 01183227312. Received date: September 06, 2020; Accepted date: November 03, 2020; Published date: November 06 , 2020

Citation: Tilling L. (2020) Hydroxychloroquine and risk of cardiac decompensation. International Journal of Clinical Case Reports and Reviews. 4(2); DOI:10.31579/2690-4861/053

Copyright: (c) 2020 Lindsey Tilling, This is an open-access article distributed under the terms of the Creative Commons Attribution License, which permits unrestricted use, distribution, and reproduction in any medium, provided the original author and source are credited.

\section{Abstract}

Background: Hydroxychloroquine (HCQ) is a 4-aminoquinoline derivative, used in the treatment of malaria and rheumatic diseases. HCQ has also been suggested as a treatment in patients suffering from severe acute respiratory syndrome-coronavirus 2 (SARS-CoV-2). One of the cardiac complications of SARS-CoV-2 is myocarditis and ventricular dysfunction.

Case summary: We present the case of a 52 year old lady presenting with 2 months history of breathlessness, found to have severely impaired left ventricular function. She had been taking HCQ for 28 months for seronegative inflammatory arthritis. No cause was identified on initial investigation. She was treated with optimal medical therapy, and HCQ was stopped. After 5 months a cardiac MRI scan revealed full remodelling of the ventricle.

Discussion: This case highlights one of the lesser recognized side effects of HCQ, and the potential for severe cardiac dysfunction. As this drug continues to be investigated and used in the management of SARS-CoV-2 it is important to recognize the potential for cardiac decompensation in patients who are already at increased risk of myocardial dysfunction.

Keywords: hydroxychloroquine; covid-19; systolic impairment

\section{Learning Points}

1. Hydroxychloroquine can cause severe ventricular systolic impairment, which may resolve on withdrawal of the agent

2. Patients hospitalized with SARS-CoV-2 are more likely to have pre-existing cardiovascular conditions, and have also been shown to be at increased risk of cardiac decompensation

3. Clinicians must be aware of the risks to cardiac function when using hydroxychloroquine in the treatment of patients with SARS-CoV-2.

\section{Introduction}

Hydroxychloroquine (HCQ) is a 4-aminoquinoline derivative, used in the treatment of malaria and rheumatic diseases. HCQ has also been suggested as a treatment in patients suffering from severe acute respiratory syndrome-coronavirus 2 (SARS-CoV-2). Activity against coronavirus and influenza has been demonstrated in vitro, and in small clinical studies, the majority uncontrolled. SARS-CoV-2 typically presents with cough, fever and fatigue, although other presentations are recognised, including heart failure and myocarditis.

There is understandable urgency in finding a treatment for this disease which has significant mortality, but concern persists regarding the efficacy of HCQ in the management of SARS-CoV-2, and also the potential for harm. Side effects of HCQ are rare, but may include adverse effects on the eye, gastrointestinal tract, and skin. Arrhythmia, and prolongation of the QT interval are recognized as the main cardiac adverse events, with cardiomyopathy infrequently recorded.

\section{Timeline}

\begin{tabular}{|l|l|}
\hline Index date & $\begin{array}{l}\text { Patient admitted with breathlessness, found to have severe left ventricular (LV ) } \\
\text { dysfunction on echocardiogram, ejection fraction 15\% }\end{array}$ \\
\hline 5 Days & Discharged after diuresis and initiation on heart failure medication \\
\hline 3 weeks & Reviewed in heart function clinic, medication increased and HCQ discontinued \\
\hline 5 months & Cardiac MRI scan showed full remodelling of left ventricle, EF 55\% \\
\hline
\end{tabular}

\section{Case presentation}

A 52 year old female teaching assistant presented to the emergency department with 2 months of exertional breathlessness. Her exercise tolerance had significantly diminished from normal to only 10 yards. She also reported non-exertional chest and abdominal pains. She had a background of controlled hypertension, fibromyalgia, and seronegative inflammatory arthritis, for which she had been taking methotrexate for 2 years, and HCQ 200mg twice daily for 28 months. Grade 2, ER positive, HER2 negative invasive ductal carcinoma had been diagnosed 18 months earlier, and treated with wide local excision and radiotherapy. Other medications included indapamide, amlodipine, anastrozole and gabapentin. 
There was no family history of ischaemic heart disease, cardiomyopathy or sudden death in her family. She was previously fully independent, was a non-smoker, and reported infrequent alcohol consumption.

On examination weight was $95 \mathrm{~kg}$ and BMI 35, temperature 36.9. Pulse 108 beats per minute, blood pressure $132 / 91 \mathrm{mmHg}$, oxygen saturations $98 \%$ on air. Right base crepitations were audible, with otherwise unremarkable cardiovascular and abdominal examination.
Blood tests revealed a normocytic mild anaemia, normal renal function, and deranged liver function which became progressively worse during admisson, but had resolved by the first clinic appointment post discharge. At peak ALP was 175IU, ALT 1643IU. D Dimer was also elevated at $2696 \mathrm{mg} / \mathrm{ml}$, troponin $\mathrm{T}$ slightly high at 26ng/L and NTproBNP $1450 \mathrm{pg} / \mathrm{ml}$ (table 1). Autoimmune screen was negative as were hepatitis and HIV screen, and iron studies and thyroid function were normal.

\begin{tabular}{|l|l|l|l|l|l|l|l|}
\hline & $\begin{array}{l}\text { Reference } \\
\text { value }\end{array}$ & Day1 & Day3 & Day 5 & Day 7 & Day 9 & Day 31 \\
\hline $\begin{array}{l}\text { Haemoglobin } \\
\text { (g/L) }\end{array}$ & $115-180$ & 108 & 112 & 110 & 126 & 121 & 125 \\
\hline $\begin{array}{l}\text { White blood cell } \\
\text { count (x10 })\end{array}$ & $3.5-11$ & 6.51 & 6.85 & 7.62 & 4.92 & 5.25 & 4.56 \\
\hline $\begin{array}{l}\text { Platelet count } \\
(\mathbf{x 1 0})\end{array}$ & $150-450$ & 211 & 211 & 119 & 144 & 140 & 173 \\
\hline D- dimer (ng/ml) & $<500$ & 2696 & 2388 & & & & \\
\hline $\begin{array}{l}\text { eGFR } \\
\text { (mL/min/1.73m })\end{array}$ & $>60$ & 63 & 71 & 78 & 85 & 90 & 86 \\
\hline $\begin{array}{l}\text { Bilirubin } \\
\text { (umol/L) }\end{array}$ & $<21$ & 5 & 18 & 22 & 13 & 7 & 9 \\
\hline ALP (U/L) & $35-104$ & 97 & 127 & 175 & 155 & 121 & 100 \\
\hline ALT (U/L) & $1-34$ & 135 & 443 & 1643 & 1014 & 594 & 52 \\
\hline Troponin (ng/l) & $<14$ & 25 & 26 & & & & \\
\hline $\begin{array}{l}\text { NTproBNP } \\
\text { (pg/ml) }\end{array}$ & $<400$ & 1450 & & & & & \\
\hline
\end{tabular}

Table 1: Laboratory values during inpatient stay (day 1-9) and at first clinic visit (day 26)

Abbreviations: eGFR estimated glomerular filtration rate; ALP alkaline phosphatase; ALT alanine aminotransferase; NTproBNP N-terminal prohormone $\mathrm{B}$ natriuretic peptide

Her ECG showed a sinus tachycardia, with T wave inversion in V1-4 (Figure 1)

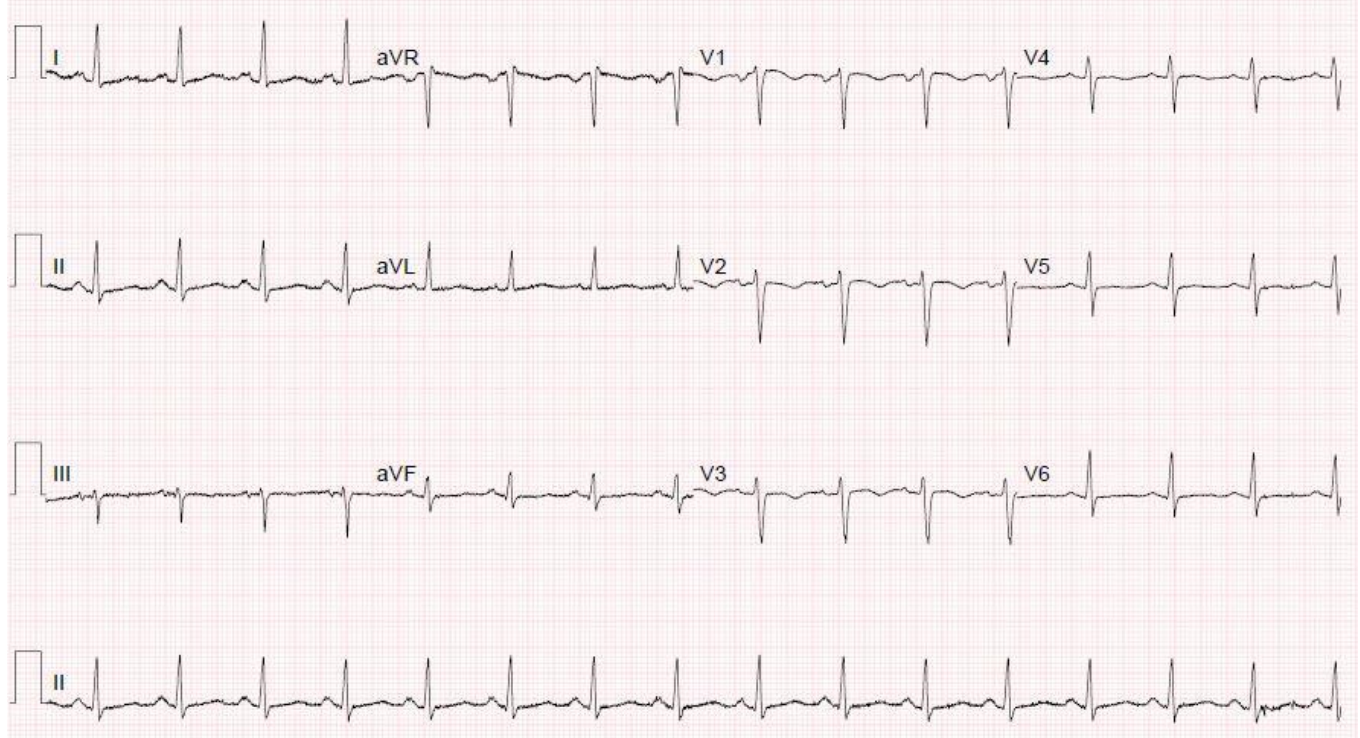

Chest xray was unremarkable. CT pulmonary angiogram showed no pulmonary emboli, a small right sided pleural effusion, and otherwise clear lung fields. Ultrasound of the abdomen showed a mildly fatty abdomen only.

Transthoracic echo demonstrated a severely impaired left ventricle, with septal dyskinesis, overall ejection fraction estimated at $15 \%$. The right heart was also impaired, and there was evidence of moderate functional mitral regurgitation and tricuspid regurgitation (Video 1,2 and 3).

\section{Management}

The patient was treated with intravenous diuretics and commenced on ramipril $2.5 \mathrm{mg}$ once daily and bisoprolol $5 \mathrm{mg}$ twice daily. Methotrexate was stopped in view of the liver dysfunction, and her liver dysfunction improved during the admission. At clinic review 3 weeks post discharge 
she remained very breathless. Ramipril was increased to $3.75 \mathrm{mg}$ once daily, ivabradine $5 \mathrm{mg}$ twice daily initiated, and she was advised to discontinue HCQ in view of the potential for drug-induced cardiomyopathy. 5 months later she underwent a cardiac MRI scan. This demonstrated a fully remodelled left and right ventricle, with no late gadolinium enhancement of the left ventricle. (Video 3 and 4).

Our patient reported some improvement in her symptoms of breathlessness when reviewed 5 months after initial diagnosis, and there has been no progression in her rheumatological symptoms. She remains on heart failure medication.

\section{Discussion}

This patient presented in decompensated, newly diagnosed heart failure with severely reduced ejection fraction. Withdrawal of a medication which is known to cause cardiac failure led to full remodelling of the ventricles, and this, in the absence of any other cause of heart failure leads us to believe HCQ to be causative.

HCQ-induced cardiomyopathy has been associated with female gender, older age, prolonged duration of therapy and pre-existing cardiovascular disease. Pre-existing cardiac disease has also been recognised as a risk factor for worse outcomes for patients with SARS-CoV-2 [1, 2].

Initial echocardiogram findings in HCQ-induced cardiomyopathy may include hypertrophy, biatrial enlargement and restrictive physiology, preceding systolic impairment, which is often severe [3]. In cases where the diagnosis is unclear, cardiac biopsy has been carried out; the characteristic findings are of diffuse myocyte vacuolization without myocarditis on histology, and sarcoplasmic myelinoid and curvilinear bodies on electron microscopy [4]. One recent case report noted that, within 6 months of drug withdrawal, cardiomyocytes were reduced in size and devoid of intracellular vacuoles and myelin and curvilinear bodies were replaced by new contractile elements [5].

Cardiomyopathy associated with HCQ use can be fatal. In a review of 25 patients taking HCQ or chloroquine and new onset heart failure 12 ceased therapy, 8 of these improved clinically, and 4 required cardiac transplantation, or died [6]. It is suggested that failure to recognise HCQ induced cardiomyopathy may contribute to poorer outcomes, as a result of delayed diagnosis.

The FDA has very recently authorized HCQ for use in patients hospitalized with SARS-CoV-2. This was following small studies which indicated reduced time to clinical recovery, and in this setting, HCQ was only given for short periods, typically $<7$ days [7]. It is worth noting that these patients may however have pre-existing cardiovascular disease. SARS-CoV-2 itself may predispose to cardiac decompensation; the incidence of heart failure has been recorded as between $23-33 \%$ in severely- critically ill hospitalized patients $[8,9]$. It is therefore important to monitor closely for heart failure, which could be exacerbated by the presence of HCQ. Secondly, there has been some suggestion of prophylactic use of HCQ against SARS-CoV-19 infection; if this translates into clinical practice, then there will have to be robust processes for assessing cardiovascular risk in HCQ recipients.
This case highlights one of the lesser recognized side effects of HCQ, and the potential for severe cardiac dysfunction. As this drug continues to garner interest as a potential weapon in the battle against SARS-CoV-19, it is important to recognize the potential for cardiac decompensation in patients who are already at increased risk of myocardial dysfunction.

\section{Funding}

No funding was received for this article

\section{Acknowledgements}

We acknowledge the contribution from Dr Andrew Elkington in providing the cardiac MRI scans of this patient

\section{First Author biography}

Dr Lindsey Tilling (BSc, MRCP, $\mathrm{PhD}$ ) is a consultant cardiologist at the Royal Berkshire hospital, and is the lead for heart failure. She has a specialist interest in all aspects of heart function, cardiomyopathy, and device therapy.

\section{References}

1. Guan W Ni Z Hu Y et al. (2020) Clinical characteristics of coronavirus disease 2019 in China. N Engl J Med.

2. Zhang JJ Dong X Cao YY et al. (2020) Clinical characteristics of 140 patients infected by SARS-CoV-2 in Wuhan, China. Allergy.

3. Cotroneo J, Sleik KM, Rene Rodriguez E, et al. (2007) Hydroxychloroquine-induced restrictive cardiomyopathy. Eur J Echocardiogr; 8: 247-251.

4. Keating R, Bhatia S, Amin S, et al. (2005) Hydroxychloroquine-induced cardiotoxicity in a 39-year-old woman with systemic lupus erythematosus and systolic dysfunction. J Am Soc Echocardiogr. Sep; 18(9):981.

5. Frustaci A, Morgante E, Antuzzi D, et al. (2012) Inhibition of cardiomyocyte lysosomal activity in hydroxychloroquine cardiomyopathy. Int J Cardiol; 157: 117-119.

6. Costedoat-Chalumeau N, Hulot JS, Amoura Z, et al. (2007) Cardiomyopathy related to antimalarial therapy with illustrative case report. Cardiology; 107: 73-80.

7. Gautret P, Lagier JC, Parola P et al. (2020) Hydroxychloroquine and azithromycin as a treatment of COVID-19: results of an open-label non-randomized clinical trial. Int J Antimicrob Agents.

8. Zhou F, Yu T, Du R et al. (2020) Clinical course and risk factors for mortality of adult inpatients with COVID-19 in Wuhan, Chain; a retrospective cohort study. Lancet Vol 395 issue 10229 P 1054-1062.

9. Arentz M, Yim E, Klaff L et al. (2020) Characteristics and Outcomes of 21 Critically Ill Patients with Covid19 in Washington State. JAMA 2020.

10. Hydroxychloroquine Chemoprophylaxis in Healthcare Personnel in Contact With COVID-19 Patients (PHYDRA Trial) (PHYDRA) ClinicalTrials.gov Identifier: NCT04318015. 